\title{
THE ANTIDOTE
}

You know that line they hand you About the rest of your life

Beginning today? Well, it's true.

$$
\text { O U T O Y U }
$$

Coming out of you

I feel like Democracy in America

slowly slipping away

\section{DEATH OF THE ROMANTIC}

Cut his tongue

Kissing a girl

On the contact lens.

\section{O M E B A C K}

Whose are the hoses?

Whose are the roses?

Whose the houses?

Nobody knows.

Now it comes back to me!

They belong to the factory!

Whose is the factory?

Nobody knows. 